\title{
"Hemos aprendido que los hombres no son más importantes que las mujeres". Una investigación sobre la construcción de una escuela coeducativa en Cantabria (España)*
}

\author{
Ángela SAIZ LINARES** \\ Noelia CEBALLOS LÓPEZ ${ }^{* * *}$
}

\begin{abstract}
Resumen
Este artículo tiene por objeto visibilizar algunas claves curriculares y organizacionales esenciales para avanzar hacia un modelo de escuela coeducativa. Para ello, adoptando un enfoque etnográfico, se plantean los resultados más relevantes de una investigación realizada en una escuela pública española que constituye un ejemplo paradigmático de una escuela que emprende reflexiones y acciones explícitamente destinadas a eliminar las discriminaciones debidas al género y a construir otros modelos de masculinidad y de feminidad.
\end{abstract}

Palabras clave: Coeducación, Organización Escolar, Currículum, Etnografía.

\footnotetext{
* Recibido el 28 de mayo de 2019, aceptado el 21 de octubre de 2020.

** Departamento de Educación, Universidad de Cantabria,Santander, Cantabria, España. saizla@unican.es / https://orcid.org/0000-0001-9226-9346

*** Profesora auxiliar en la Universidad de Cantabria, Santander, Cantabria, España. ceballosn@unican.es/ https://orcid.org/0000-0001-6962-8566
} 
"We Learned that Men Are No More Important Than Women". A Study of the Construction of a Co-Educational School in Cantabria (Spain)

\section{Abstract}

The purpose of this paper is to raise awareness about some essential curricular and organizational issues, that help advance towards a model for coeducational schools. Under an ethnographic approach, we present the most important results of a study conducted in a Spanish public school, which is a paradigmatic example of a school that undertakes reflections and actions that explicitly strive to eliminate gender discrimination and build other models of masculinity and femininity.

Keywords: Coeducation, School Organization, Curriculum, Ethnography. 


\section{Introducción}

En este artículo abordamos la equidad de género en el ámbito educativo, pues sabemos que este discurso se ha emplazado en las escuelas con más éxito que la práctica (Simón, 2010; Subirats, 2017), necesitando actualmente actuaciones y contenidos orientados a la educación para la equidad. Al abrigo de esta necesidad, en este artículo analizamos un ejemplo paradigmático ${ }^{1}$ de escuela que camina hacia un enfoque coeducativo con el fin de ofrecer algunas claves curriculares y organizacionales esenciales para avanzar hacia un modelo de coeducación.

\section{La igualdad ${ }^{2}$ de género en la legislación}

Gracias a las reivindicaciones feministas y a los estudios de género, muchas han sido las conquistas en materia de igualdad entre hombres y mujeres (educación, trabajo, familia, vida pública...). Estos avances se reflejan también normativamente en el ámbito internacional y nacional (Aristizabal et alii, 2018), destacando, especialmente, la Convención sobre la Eliminación de Todas las formas de Discriminación Contra la Mujer (CEDAW), celebrada en 1979 y pactada por los diferentes gobiernos en el marco de la Organización de las Naciones Unidas. El artículo 10 de esta Declaración se orienta expresamente al ámbito educativo, consignándose la modificación de los libros, programas escolares y métodos de enseñanza para eliminar los conceptos estereotipados en la esfera de la educación. Por otro lado, la IV Conferencia Mundial de Mujeres (Pekín, 1995) supone un punto de inflexión al reconocer la igualdad de hombres y mujeres como un asunto nuclear en el desarrollo de las políticas sociales donde su desarrollo debe impulsarse a través de una estrategia transversal de género que implique todos los ámbitos, incluido el educativo (Grañeras et alii, 2015),

Otras leyes relevantes en materia de igualdad de género en España son la Ley para promover la conciliación de la vida familiar y laboral de las personas trabajadoras (Ley 39/1999, de 5 de noviembre), la Ley de Medidas de Protección Integral contra la Violencia de Género (Ley Orgánica 1/2004, de 28 de diciembre), la Ley para la igualdad efectiva de mujeres y hombres (Ley Orgánica 3/2007, de 22 de marzo) o el reciente Pacto de Estado en materia de Violencia de Género 2017.

Direccionando la mirada hacia la legislación educativa española, encontramos luces y sombras en las últimas leyes promulgadas. La Ley Orgánica 2/2006, de 3 de mayo, de Educación (LOE) estableció como una prioridad los principios de igualdad de derechos y oportunidades entre mujeres y hombres y la no discriminación, y creó áreas curriculares específicas para su desarrollo (Grañeras et alii, 2015). Asimismo, instituyó la incorporación de una persona de referencia dentro de las escuelas con las funciones de promoción de la igualdad real y efectiva entre mujeres y hombres. En oposición, la última Ley Orgánica 8/2013, de 9 de diciembre, para la mejora de la calidad educativa (LOMCE), vigente actualmente, ha significado la modificación de algunas de las líneas nucleares trazadas por la LOE. Si bien a nivel declarativo reconoce la igualdad de derechos y oportunidades, reduce algunas de las líneas de acción existentes: elimina o modifica las materias educativas que trabajan por la igualdad de género y recoge la posibilidad de financiar a los centros educativos que segreguen por sexo (Grañeras et alii, 2015).

A pesar de los avances sociales y normativos logrados en materia de igualdad, todavía queda un largo camino para conseguir una verdadera equidad, encontrando formas de discriminación sutiles edificadas en estereotipos de género ${ }^{3}$ hondamente alojados que privilegian lo masculino

\footnotetext{
1 El CEIP Manuel Llano, en Santander (España), há ganado en 2018 el Premio Nacional de Educación para El Desarrollo "Vicente Ferrer", em su X edición, por su trabajo em el curso 2017-2018, entre otras cuestiones, sobre el Objetivo de Desarrollo Sostenible (ODS) orientado a Lograr la igualdad entre los géneros y empoderar a todas lãs mujeres y niñas.

2 Según Naciones Unidas, la igualdad de género refiere a "la igualdad de derechos, responsabilidades y oportunidades de lãs mujeres y los hombres, y lãs niñas y los niños", sin que el sexo suponga un motivo de discriminación. La equidad agrega un elemento ético para asegurar una igualdad real que compense la desigualdad histórica y estructural del género femenino en el ámbito laboral, educativo, de la salud, el económico, cultural y social.

3 Sobre La mujer normativa se ha dibujado un retrato con rasgos emparentados com lo expresivo (cuidado, afecto y sensibilidad -por encima de la razón-, dependencia), mientras que em los hombres normativos esos trazos se relacionan con rasgos instrumentales (fuerza, racionalidad, independencia). De ahí que las mujeres aparezcan subrepresentadas en
} 
sobre lo femenino (Fernández-González y González-Clemares, 2015; Pallarès, 2012), hasta otras formas más hostiles y agresivas de actuación hacia la mujer, como la violencia de género (De la Peña, 2007). El peligro reside en que estas disposiciones culturalmente construidas ${ }^{4}$ se naturalizan y adquieren la apariencia de diferencias biológicas, contribuyendo a sostener una relación desigual de poder donde la mujer mantiene un papel subsidiario y subordinado en relación a los hombres. Este sistema sexo-género se edifica en un modelo social androcéntrico y patriarcal ${ }^{5}$ y está en la base de la aparición y perpetuación de desigualdades sociales, políticas, económicas, etc. entre hombres y mujeres (Ballarín, 2001).

\section{Igualdad y equidad de género y educación}

Aparentemente la escuela constituye una institución social sin discriminaciones sexistas, en contraste con otros contextos más hostiles para las mujeres, como el laboral o el familiar (GarcíaLastra, 2017). Resulta imprescindible destacar los logros educativos que han posibilitado transitar desde la exclusión de las mujeres en el sistema educativo hasta la escuela mixta que tenemos hoy en día, que defiende un mismo espacio y un mismo currículum para niños y niñas donde tienen los mismos derechos y deberes en teoría (Calvo et alii, 2011).

Sin embargo, una mirada más fina muestra cómo los estereotipos y desigualdades dejan su sedimento en la experiencia escolar, articulada desde un modelo masculino. Por ejemplo, mientras las estadísticas refrendan mejores resultados escolares de las niñas frente a los niños, a la hora de incorporarse al mundo laboral las mujeres tropiezan con más obstáculos, ocupando puestos de menor remuneración y/o responsabilidad (Subirats, 2016), lo que se viene denominando "techo de cristal" (Morrison et alii, 1987). En la misma línea, a pesar de estar la profesión docente altamente feminizada, especialmente en la etapa de Infantil, los puestos directivos suelen estar monopolizados por los hombres (Anguita y Torrego, 2009; Eurydice, 2010) lo que refuerza un currículum oculto que ahonda en la división de trabajos (Camps y Vidal, 2015; Drudy, 2008). Las decisiones académicas de futuro también se encuentran fuertemente influenciadas por los estereotipos de género, orientando a las mujeres a carreras que dilatan las funciones domésticas (cuidado, enseñanza y servicio) (Aristizabal et alii, 2017; Quinn, 2015) y que preservan su papel secundario en el mundo público (Subirats, 2016). Por otro lado, los currículos escolares siguen teniendo una orientación androcéntrica que estereotipifica, subrepresenta o invisibiliza a la mujer y sus contribuciones a lo largo de los siglos, hecho especialmente encarnado en los libros de texto (LópezNavajas, 2014; Parra, 2009; Torres, 2008). También comprobamos el dominio de los varones de los espacios escolares -los niños aprenden a ocupar los espacios centrales del patio y a emplearlos para actividades que implican movimiento como el fútbol, mientras las niñas tienden a agruparse en rincones y a realizar actividades de carácter estático (Tomé, 2017)-, un trato desigual con respecto a la atención, actitudes y expectativas del profesorado hacia alumnos y alumnas (Camps y Vidal,

âmbitos profesionales tradicionalmente masculinizados (informática, electricidad, electrónica, etc.) y de mayor estatus, higherprofessions, y sobrerrepresentadas en sectores tradicionalmente feminizados (enfermería, trabajo social, magisterio...), denominadas semi-profesiones o lowerprofessions (Swain, French y Cameron, 2003).

4 Ya Simone de Beauvoir (1981) em su obra "El segundo sexo", nos advierte de que no se nace mujer, sino que se llega a serlo. Em otras palabras, mientras el término sexo designa a una categoría meramente orgánica, biológica, el término género alude a una categoría sociocultural referida al rol que elvarón o La mujer desempeñan em La sociedad. Como señala Joan Scott (1986), el género constituye finalmente un sistema de organización y jerarquización social.

${ }^{5}$ Entendemos patriarcado como "La manifestación e institucionalización Del dominio masculino sobre lãs mujeres y niños/as de La familia y La ampliación de esse dominio sobre lãs mujeres em La sociedad en general” (Lerner, 1990). Esta estructura patriarcal podemos hallarla en el origen de los sistemas de organización social y política y se vertebra a partir de los vínculos de parentesco, de un lado, y de La heterosexualidad y el contrato sexual, que sirvesirven para El fin reproductivo y es condición ineludible para La continuación del patriarcado (Fontela, 2008). De ahí que algunas autoras apuesten La nominación, más precisa, de heteropatriarcado (Jeffreys, 1996). Esta ideologia heteropatriarcal forma parte de todas lãs civilizaciones históricas y está fuertemente instalada em las culturas (Millet 2010), de modo que em los estados modernos seguimos encontrando una dominância Del varón sobre La mujer que obstaculiza suconstitución como sujetos políticos. Igualmente, La capacidad reproductiva de lãs mujeres sigue postulándose como base de dicha opresión social (Firestone, 1976). Estas conceptualizaciones, como señala Fontela (2008), han dado lugar al desarrollo de las distintas corrientes del feminismo (radical, marxista, materialista, etc.). 
2015) y un uso sexista del lenguaje con el predominio del masculino genérico (García-Lastra, 2017; López-Navajas 2014; Subirats 2016).

Esta socialización diferenciadora desde la más pronta infancia a través de las diversas "tecnologías del género" (Lauretis, 1987) tiene como resultado que, desde muy pequeños, los niños y niñas comienzan a identificar las conductas que son apropiadas para su género: los "mandatos de género" (Martínez y Ramírez, 2017). Así, los niños tienden a representar en la escuela un esquema estereotipado de dureza, agresividad y actividad, mientras las niñas configuran una subcultura de la inactividad y una resistencia sutil a las normas escolares. Además, para las niñas resulta más fácil incumplir la norma de género que para los niños, quienes son más penalizados por hacerlo (Álvarez et alii, 2017). Consecuentemente, la autosegregación sexual (Camps y Vidal, 2015; Pellegrini et alii, 2007) se reconoce como un fenómeno generalizado en las primeras etapas escolares, implicando pautas de organización de los grupos y juegos diferenciados.

Si bien este proceso de socialización tiene consecuencias profundas para la configuración de identidades, diversos estudios (Bragg et alii, 2018; Fisher y Jenson, 2017; Ruiz-Repullo, 2017) reivindican la capacidad de agencia de los menores, "construyendo, negociando y rechazando activamente las masculinidades y feminidades hegemónicas" (Bragg et alii, 2018:2). De otra parte, en los últimos años la cultura popular ofrece referentes que desafían lo género y heteronormativo (celebridades, influencers, youtubers, etc.), así como un vocabulario en expansión que contribuye a cierta contrasocialización de género. Asimismo, han surgido comunidades en línea que constituyen espacios de apoyo y autoafirmación (Albury y Byron, 2016; Bragg et alii, 2018; Kim y Ringrose, 2018).

En cualquier caso, la escuela sigue constituyendo un espacio privilegiado para controvertir las desigualdades sexistas y configurar otro modelo socioeducativo. Fruto de estas necesidades florece la noción de coeducación, que trasciende la idea de escuela mixta para entender que, además de la presencia de las mujeres en la escuela, necesitamos llevar a cabo actuaciones expresamente destinadas a eliminar las discriminaciones en razón del género y a replantear los modelos de masculinidad y de feminidad hegemónicos (Ballarín, 2011) con objeto caminar hacia la construcción de modelos menos limitantes, más diversos y, sobre todo, más igualitarios. En otras palabras, una escuela coeducativa examina los modelos patriarcales heredados $e$ indaga en qué medida estos están aún presentes en el currículo, en las maneras de estar en aulas y patios, en el mundo exterior. Por eso, entre los desafíos de una escuela educativa está la modificación del lenguaje, la transformación de los currículos incorporando contenidos referidos a la igualdad y equidad de género, el replanteamiento de los espacios escolares, el análisis de los materiales didácticos (por ejemplo, visibilizando a las mujeres en la historia, incidiendo en sus ausencias en la tradición cultural transmitida e indagando sobre lo que hay detrás de estos soterramientos), etc. (Fernández-González y González-Clemares, 2015; Esteve, 2013; Moriana, 2017; Simon, 2010).

\section{Metodología}

Explorar un escenario tan complejo requiere indagar la realidad de las escuelas a partir de lo que lo que en ellas se vive. Concretamente, nuestro propósito es comprender en profundidad y "desde dentro" algunas claves curriculares y organizacionales que permiten al centro educativo objeto de estudio navegar hacia el horizonte de la coeducación y ofrecer algunas ideas inspiradoras para otras escuelas. Consecuentemente, nos situamos en una investigación cualitativa con perspectiva etnográfica (Angrosino, 2012; Restrepo, 2016).

El centro educativo analizado es de titularidad pública, situado en una zona periférica de Santander (España) en la que confluyen varios barrios de características diversas dando lugar a un alumnado heterogéneo en cuanto a su origen social, cultural y económico. El proyecto educativo de la escuela presenta un claro compromiso con la atención a la diversidad. Con este propósito, dicho centro desarrolla un proyecto encuadrado en el marco de la Acción Tutorial (las Tutorías Compartidas) que se orienta a mejorar la convivencia y que implica a docentes y alumnado de educación primaria (6-12 años). Para ello se genera un espacio de trabajo inter-nivelar (grupos con alumnos de diferentes cursos) que ocurre quincenalmente para realizar actividades en torno a diferentes temáticas que persiguen desarrollar el sentido de pertenencia, la construcción de una 
identidad positiva, la cooperación, el respeto y, en resumidas cuentas, apoyar, atender y celebrar la diversidad. La temática para el curso que realizamos el trabajo de campo, 2017-2018, es la "igualdad de género" (tal y como lo denominan en el centro), escogida por su relevancia social y por su trascendencia para la atención a la diversidad.

Nuestra relación con esta escuela es estrecha y prolongada en el tiempo. Comienza en 2010, cuando nuestro equipo de investigación de la Universidad de Cantabria inicia junto con el centro educativo un proyecto de investigación sobre participación estudiantil, que dura unos 4 años. Tras el mismo, el equipo de investigación fue trasladando progresivamente la responsabilidad a los actores del centro, aunque el contacto con la escuela continuó. En el curso 2017-2018 dos de las investigadoras regresamos al centro y realizamos una nueva sumersión etnográfica con el propósito de analizar uno de los proyectos de participación generados: las Tutorías Compartidas, que como hemos dicho se vertebraron sobre la igualdad de género.

La negociación y el acceso al campo son momentos clave de la etnografía y, para este propósito, comenzamos contactando con la dirección del centro con el objetivo de exponer de manera detallada y transparente el propósito de esta investigación y las implicancias de participar. Tras ser autorizadas por el equipo directivo, nos reunimos en otra sesión con los docentes implicados para, en primer lugar, explicar la investigación y, de otra parte, para consensuar los tiempos y situaciones de observación que sucederían.

La etnografía requiere la vinculación estrecha con las personas que son objeto de estudio y un conocimiento profundo del contexto (Velasco y Díaz de Rada, 2006), por lo que realizamos una estancia prolongada en el campo acudiendo de manera quincenal al centro educativo.

Las técnicas de producción de información son las propias de la investigación etnográfica: entrevistas semiestructuradas, observaciones, grupos de discusión y análisis documental:

- Las observaciones ${ }^{6}$ se produjeron de forma recurrente durante todo el curso académico y nos permitieron recoger los datos en su medio natural, así como mantener un contacto constante con los sujetos (Velasco y Díaz de Rada, 2006). En total se realizaron 8 observaciones, una por cada Tutoría Compartida celebrada. Además, acudimos a observar ambas investigadoras con objeto de abarcar más tramas de observación. Los instrumentos utilizados para registrar los datos fueron las notas de campo y los diarios.

- Los grupos de discusión (GD), de 6 participantes cada uno, se desarrollaron una vez hubo concluido el proyecto y tuvieron un sentido evaluativo de la iniciativa. Estuvieron conformados por profesorado (maestros, orientadora, jefa de estudios y directora) y por alumnado (desde $1^{\circ}$ de Primaria hasta $6^{\circ}$ ) que había participado en el Proyecto. En total se realizaron $4 \mathrm{GD}$, que fueron grabados y posteriormente transcritos. Todos ellos se llevaron a cabo en diferentes espacios del centro escolar (en aulas y en la biblioteca) y contaron con una duración aproximada de 90 minutos con los profesionales educativos y unos 45 minutos con los alumnos.

- Igualmente se realizaron 2 entrevistas semiestructurada a informantes clave, con objeto de acceder a informaciones adicionales y matizar algunas cuestiones evocadas en los GD (Kvale, 2011). Elegimos, para ello, a dos docentes veteranas en el centro educativo. También se grabaron en audio y tuvieron una duración de unos 45 minutos.

- Por último, se analizaron documentos institucionales del centro (Proyecto Educativo de Centro y Plan de Acción Tutorial) que suministraban contexto y apoyo a la observación.

Finalmente, realizamos la interpretación de la información recogida a partir de un proceso de codificación temática (Angrosino, 2012) haciendo uso del programa MaxQDa.

\footnotetext{
${ }^{6}$ Las investigadoras no hemos participado como integrantes de lãs sesiones de Tutorías Compartidas y nuestro papel se ha relegado a observar y registrar las notas de campo. Cabe destacar que esta escuela abre frecuentemente sus puertas a personas de La comunidad para diferentes actividades y se aprecia una habituación grande Del alumnado a la presencia de otras personas invitadas en sus clases o el centro.
} 


\section{Resultados}

\section{Construcción de un equipo sensible con la equidad de género: equipos impulsores.}

La acción educativa por la igualdad y la equidad de género es una empresa compleja, pues las desigualdades están ancladas en las raíces más profundas del contexto social, pero también de la cultura escolar ${ }^{7}$. Por ello, la acción aislada o personalista se presenta como parcial e insuficiente. Es la acción colectiva que aúna esfuerzos la que permite penetrar en las acciones del día a día y en la estructura y cultura escolar.

Este es uno de los ejes centrales del proyecto de la escuela estudiada: la creación de redes de colaboración a través de los equipos impulsores. Estos equipos congregan a personas con una sensibilidad común por diferentes aspectos. En el curso 2017/2018, el equipo impulsor de acción tutorial, especialmente sensibilizado con la igualdad de género, eligió este asunto como núcleo de sus acciones.

El Manuel Llano es un centro sensible a todo lo que acontece, la igualdad de género está ahí y nos preocupa mucho trabajarla. La tutoría compartida es la acción tutorial del centro [...] Y la igualdad de género es una pata a tener en cuenta en la acción tutorial (Entrevista maestra1).

Es en el seno de este equipo impulsor desde el que inician las acciones dirigidas al centro en su conjunto. El equipo impulsor tiene entre sus propósitos sensibilizar y ampliar la formación y reflexión del claustro, en esta ocasión, sobre la temática del proyecto de tutorías.

El segundo de esos pilares tiene que ver con convertirnos en un centro sensible a la detección y erradicación de cualquier situación de exclusión (Proyecto Educativo de centro).

Para ello, el equipo impulsor comparte con el resto de docentes las actividades a desarrollar con el alumnado.

Si va a haber alguna tutoría compartida nos juntamos un par de días antes [...] Hacemos una reunión para comentar cómo va a ir la tutoría compartida (GD docentes).

En este momento, es cardinal destacar el sentido profundo de cada tutoría y cómo las preguntas y materiales facilitados generan reflexiones sobre los procesos de discriminación existentes. Esta fase inicial permite a los maestros conocer recursos, sensibilizarse, pero también compartir reflexiones y preguntas al respecto.

En un segundo orden, el centro Manuel Llano ha llevado a cabo un análisis de su contexto, estructura y cultura escolar con una mirada sensible al género atendiendo a: los materiales curriculares, el lenguaje, las interacciones o el uso de los espacios escolares. Ilustramos un ejemplo en relación a las interacciones entre el alumnado:

Es un curso $\left(5^{\circ}\right)$ en el que por sistema los niños no quieren saber nada de las niñas ni las niñas de los niños. Si tú les dejas libertad, no se ponen juntos. [...]. (Entrevista maestra1)

Esta mirada analítica con perspectiva de género también atiende a las interacciones que los docentes tienen con el alumnado desvelando que, en ocasiones, existe un trato desigual con respecto a las actitudes y expectativas del profesorado hacia alumnos y alumnas (Camps y Vidal, 2015).

Sí hemos puesto en marcha muchas cosas que tienen que ver con la organización diaria... pues hay que recoger la clase porque hemos tenido plástica y ha quedado la clase hecha una

\footnotetext{
7 Conjunto de creencias, normas, rituales, hábitos y prácticas sedimentadas a lo largo Deliempo en forma de tradiciones, regularidades y reglas no puestas en entredicho, y compartidas por los actores de La escuela. La cultura escolar proporciona así a sus miembros un marco referencial para interpretar los acontecimientos y para actuar (Viñao, 2002).
} 
porquería. Pues ya se ha acabado decir: fulanita, venga a por la escoba que hay que barrer la clase (GD docentes).

Esta mirada atenta, sensible y analítica de la realidad es la que les permitió poner en marcha una red de acciones encaminadas a construir una escuela coeducativa, tal y como se relata a continuación.

\section{Diseño de acciones: currículum y organización de los espacios}

En esta sección analizaremos críticamente las acciones fundamentales que el centro educativo emprende para favorecer la coeducación y que, en definitiva, se emplazan a revisar y eliminar las pautas sexistas y los estereotipos con objeto de modificar los modelos de masculinidad y feminidad tradicionales. Estas estrategias se orientan a dos componentes fundamentales: la transformación de los currículos y la revisión de los marcos organizativos (fundamentalmente, los espacios escolares).

Currículum

En este apartado analizamos cómo la perspectiva de género se infiltra en la planificación de los procesos de enseñanza-aprendizaje y en el diseño de los proyectos educativos del centro.

En ocasiones, esta orientación de género se pone en funcionamiento en los procesos de programación, por ejemplo, en la selección de materiales (libros de texto, cuentos...) para que no reproduzcan o incluso controviertan las discriminaciones de género:

En lengua, por ejemplo, que apenas trabajamos el libro, tenemos mucho cuidado con los materiales y textos que seleccionamos (Entrevista maestra2).

En otras, se implementan actividades y se abordan contenidos educativos destinados a reflexionar sobre las desigualdades sexistas y sobre la necesidad de construir otros modelos de género y de relación. En algunos casos, se aborda de manera transversal en diferentes áreas de conocimiento. En otros destinan espacios y tiempos específicos para tratar esta temática: espacios que permitan pensar de nuevo, desde otros referentes, lo que significa ser una mujer y ser un hombre en el contexto histórico en el que vivimos y reconocerse en otros roles, actitudes y expectativas. Este es el objetivo del proyecto de tutorías compartidas desarrollado en el curso académico 2017-2018. El equipo impulsor de acción tutorial diseña, para todo el año, actividades y dinámicas que tienen por objeto "promover la igualdad de género, luchando contra los estereotipos" y que trabajarán todos los niños de Educación Primaria (Plan de Acción Tutorial).

La primera actividad se orienta explícitamente a desmontar estereotipos (previamente trabajan sobre la significación del término "estereotipo"). Para ello, cada grupo trabaja en torno a un cuento cuyas protagonistas rompen los roles estereotipados habituales de los personajes femeninos:

En esta sesión trabajan la igualdad de género desmitificando algunos cuentos infantiles. Cada grupo de alumnos tiene una princesa de cuento que rompe con ciertos estereotipos habituales en estos personajes. En el caso de la clase que observo, este personaje es "la princesa que vestía botas de montaña". Lo primero que hacen para dar comienzo a la actividad es leer algunos pasajes del cuento. Una vez termina la lectura, la maestra les dice que "vais a hablar todos, pero tenemos que levantar la mano". Empieza hablando ella: "pues me ha parecido una princesa diferente y está guay". Hay muchas manos levantadas. Una alumna señala que ella hace todo lo que hace la princesa. Otro niño dice que la princesa es como un chico. Otro que es un poco marimacho. La maestra dialoga con ellos sobre esto, de manera muy horizontal. Todos participan [...] (Observación 1).

La segunda actividad se destina a analizar críticamente catálogos de donde tienen por misión "buscar estereotipos" en relación a los juguetes considerados de niños y de niñas, para en un 
momento subsiguiente tratar de desmontar con otros argumentos dichos estereotipos: ¿por qué un niño no puede jugar con una muñeca y una niña con un balón?

Están trabajando sobre un catálogo de juguetes y cada grupo tiene que elegir uno y explicar por qué es de chicos y de chicas. La maestra va sentándose con cada grupo. En un grupo se han separado los niños y las niñas. Les dice que tienen que trabajar juntos y decidir entre todos [...] La maestra pregunta a los niños qué juguetes les gustan de esos que dicen que son del otro sexo. Dos niñas dicen que los coches. Un niño de los pequeños dice que las barbies y otro mayor se ríe. La profesora le pregunta por qué se ríe. Otros niños dicen que a ellos también les gustan las muñecas. La maestra: "o sea, que a los niños también os gustan las muñecas. ¿Y por qué no os pedís muñecas?". Otro niño dice que a él le gusta una barbie con el pelo muy largo que se peina. Una niña dice que a su hermano le gustan las cosas de niña. La maestra dice: "igual es que no tenemos que decir que hay juguetes de niño y de niña. Aunque los señores que hacen los anuncios se empeñen (Observación 2).

En este fragmento observamos precisamente cómo el género estructura la organización concreta y simbólica de la vida social y lúdica desde que los niños y niñas son pequeños, con actividades y funciones que se identifican como propias de cada sexo y que, además, no revisten el mismo reconocimiento social (Scott, 1986).

En la tercera sesión visionan algunos anuncios publicitarios indefectiblemente sexistas (de electrodomésticos, de cervezas...), así como un vídeo donde adultos e infantes, evidenciando sus prejuicios y visión estereotipada, responden al interrogante: ¿qué significa hacer algo como una niña? El objetivo en esta sesión es continuar con el análisis de estereotipos para finalmente construir, colaborativamente, un glosario con las definiciones de términos relevantes: machismo, feminismo, igualdad, etiqueta, etc.

Alumno: También vimos unos anuncios. Por ejemplo, en uno de cerveza unas chicas abrieron su armario lleno de ropa y el de los chicos estaba lleno de cerveza.

Investigadora: ¿y por qué es eso machista?

Alumna: Porque las chicas también pueden beber cerveza.

Alumno: A mí por ejemplo no me gusta la ropa.

Alumna: Vimos otro anuncio de un chico que estaba con el taladro y la mujer tenía que limpiar lo del taladro. El hombre tenía que usar el taladro porque la mujer no sabía.

Alumna: eso se llama machismo.

(GD alumnado1)

En el tercer grupo están definiendo machismo. Hay tres chicas y un chico. Una de las chicas se ofrece a escribir. El chico dice: "machismo es que a las chicas os gusta el rosa". Otra niña señala: "a mí me gusta el azul". De repente, llama mi atención una conversación que está manteniendo el grupo que define igualdad: "aunque seamos chicos o chicas podemos compartir las mismas cosas. Que somos iguales en género".

(Observación 3)

En estas actividades iniciales se trata, en definitiva, de seleccionar materiales (vídeos, anuncios, catálogos) habituales en el mundo vivencial del alumno y también de los medios de comunicación que muestren sesgos sexistas para contribuir a la eliminación de estereotipos de géneros.

En la cuarta sesión, el propósito radica en reflexionar sobre profesiones habitualmente desempeñadas por hombres y que, en este caso, son desarrolladas por mujeres con el mismo nivel de eficacia. Para ello, invitan a mujeres de la comunidad educativa (madres de alumnos, fundamentalmente) a contar su experiencia laboral en trabajos habitualmente identificados con los hombres (pintora, conductora de camiones o autobuses, ingeniera, cuidadora de animales, jugadora de rugby, etc.).

Toma la palabra la jardinera y explica en qué consiste su trabajo: "hago las rotondas que veis, los parques. Uso máquinas como mis compañeros". Explica que es la única chica de su equipo 
pero que ella hace las mismas actividades que sus compañeros y que utiliza las mismas máquinas que ellos. Una alumna de las más pequeñas explica que "a lo mejor los chicos piensan que las chicas no somos fuertes". La jardinera apostilla que no tienen razón: "yo cojo el cesto cargado de hierba y pesa mucho". Una alumna del grupo de las medianas dice que "las chicas pueden hacer lo mismo que los chicos". Otra alumna del primer ciclo de primaria dice que" los chicos dicen que las chicas no hacen lo mismo" (Observación 5).

En la última sesión, evalúan el proyecto desarrollado (comienzan con un vídeo para recordar las tutorías) y reflexionan sobre algunos aprendizajes avanzados.

Es importante reseñar que las diferentes actividades realizadas en el grupo inter-nivelar son complementadas con otras acciones reflexivas en las clases ordinarias con su tutor de referencia, dando una unidad y coherencia al proyecto global. Una cuestión fundamental sobre la que incidir reside en favorecer la corresponsabilidad en las tareas domésticas.

En clase, por ejemplo, también pedimos a los chicos/as que observen qué ven ellos en casa, cómo les parece que debe ser, si tienen otros ejemplos que quieran poner. Trabajamos también definiendo algunos conceptos (GD docentes).

Es esta una idea nuclear en un centro que camina hacia la coeducación, pues es importante diseñar propuestas que traten de modificar la esencia del proyecto educativo, superando perspectivas que relegan el abordaje de problemáticas sociales a momentos puntuales o celebraciones (por ejemplo, el día de la mujer).

Asimismo, la clave en estos procesos de formación reside en su vocación dialógica, pues todas las actividades desplegadas se sirven de espacios de negociación y debate que permiten contrastar los diferentes puntos de vista y construir conocimiento colegiadamente. No se trata, por tanto, de explicar magistralmente unos contenidos referidos a la igualdad y la equidad de género, sino de crear situaciones que permitan hacer dudar, interrogar y cuestionar, reflexionar y construir a cada alumno su proceso de aprendizaje con respecto a esta temática.

De otra aparte, vemos cómo algunas actividades trascienden los muros de la escuela y suponen una apertura al entorno, implicando el trabajo colaborativo de profesores, alumnos, familias y otros agentes del medio. Esta apertura se hace visible en la sesión destinada a fracturar los estereotipos de género asociados al desempeño profesional:

La respuesta fue muy positiva porque dentro de la comunidad educativa había muchas madres que se sintieron muy bien con el tema abordado y quisieron participar. No hubo ningún rechazo por parte de ningún sector, si acaso desinterés por parte de algunos padres que simplemente no participaron (Entrevista maestra1).

Esta participación de otros agentes no es accidental, y precisa cuidar las relaciones y crear contextos acogedores que inciten a los diferentes miembros de la comunidad a implicarse, construyendo juntos una cultura sustentada en la colaboración. Construir redes de cooperación permite diseñar conjuntamente acciones y propuestas para el centro, siempre desde la aceptación de que los cambios profundos requieren formación, análisis y reflexión.

De otro lado, implicar a la familia en estos proyectos es fundamental para favorecer valores y actuaciones en el ámbito del género que estén alineadas, pues tanto el entorno familiar como el escolar son agentes de socialización primordiales que van a configurar la identidad de la infancia. Estos agentes tienen la capacidad de contribuir a transmitir estereotipos y sesgos sexistas o, por el contrario, coadyuvar a que niños y niñas construyan otros referentes de masculinidad y feminidad.

\section{Espacios académicos y no académicos}

Sabemos también la trascendencia de los espacios escolares para reproducir estereotipos de género, pero también su virtualidad para contravenir esos mandatos si se piensa en distribuciones alternativas y respetuosas con la diversidad de inquietudes, juegos e intereses. 
El profesorado de este centro manifiesta una alta conciencia sobre su función de atender y cuidar a los niños en los espacios académicos, pero, también, en los no académicos, extendiendo las actuaciones en materia de igualdad y equidad de género a todos los espacios escolares.

Es algo que en los colegios tienes que tratarlo en el día a día. Sobre todo, en los espacios libres, abiertos, en los patios (Entrevista maestra1).

En tal línea, el recreo resulta un momento crucial en la configuración de identidades y también en el desarrollo de aprendizajes, por lo que las intervenciones educativas también colocan allí su foco de incidencia. Esta máxima tiene repercusiones a la hora de pensar en los recreos, pues ningún niño/a puede quedar desplazado. Los niños y niñas deben relacionarse entre sí y ninguna actividad puede predominar por encima del resto. Es una problemática común que los niños dominen el espacio de patio, mientras las niñas suelen congregarse más estáticamente en espacios pequeños y periféricos. Los docentes de este centro, conscientes de estas inclinaciones, han dispuesto acciones para evitar esos marcajes de género:

Los niños ocupaban todo el patio jugando al fútbol e incluso niñas que querían jugar no podían. Hemos tenido que sentarnos con ellos y marcar una serie de normas, hasta el punto de que ya no hay balón para jugar al fútbol todos los días [...] Se han organizado los patios y solo un día a la semana se juega al fútbol, el resto se dedica a otros deportes, incluso hay un día en que no hay ningún deporte: hay que jugar a los juegos tradicionales. Además, también se han incluido más deportes: el fútbol ha pasado a ser un día, después hay baloncesto, hay bádminton, hay hockey, patinaje... (Entrevista maestra2)

Como sabemos, los espacios son constructos simbólicos que expiden mensajes acerca de los valores, hábitos, de las relaciones entre personas (Tomé, 2017). Por eso es fundamental prestar una atención cuidadosa a cómo se organizan y significan. Estas acciones propuestas favorecen que la comunidad educativa en su conjunto aprecie por igual tipos distintos de juegos, que implican habilidades y capacidades de distinto cariz. No se trata de vetar aquellos juegos predominantes, sino de equilibrar la divergencia de actividades lúdicas (juego tranquilo, juego de movimiento, juego de exploración y experimentación, etc.).

Sabemos, de otra parte, que esta incidencia será mayor si los alumnos son invitados a participar en los cambios. Si ellos pueden reflexionar sobre la problemática y participar en el replanteamiento de los espacios, muy previsiblemente se sentirán más responsables de su uso e interiorizarán las virtualidades de jugar niños y niñas juntos a una diversidad grande de juegos. Por eso, en el proceso de análisis y planificación previo al cambio, se invitó a los alumnos a participar a partir de la asamblea de centro:

El qué deportes se pueden poner en marcha se deciden en la asamblea de alumnos. Quizá este tema de los patios es uno de los que más ocupe en la asamblea de alumnos (Entrevista maestra2).

Esta participación es fundamental también a la hora de implementar las acciones. Por ello, los docentes delegan la labor de dinamización de dichas actividades y espacios a algunos niños, los "voluntarios de recreo", especialmente formados para este propósito:

Una de las razones por las que se organizó todo este voluntariado fue para todos esos niños que se ha comprobado que están en el patio perdidos, que en lugar de ser media hora de disfrute se convierte para ellos en una hora de sufrimiento. Los voluntarios tienen que reclamar la atención de esos niños que no saben a qué jugar, con quién jugar... (Entrevista maestra1).

Como decíamos, también son fundamentales las relaciones que se establecen en los espacios académicos. En el apartado anterior se ha identificado la tendencia a la autosegregación sexual que va apareciendo a medida que avanzan en los cursos de primaria (Camps y Vidal, 2015; Pellegrini et 
alii, 2007). Consecuentemente, es importante apostar por acciones metodológicas que contribuyan a transgredir estas inclinaciones y a establecer otro tipo de relaciones y vínculos entre niños y niñas:

Yo les estoy acostumbrando a que, por normal, los grupos deben ser mixtos, porque la diferencia enriquece al grupo [...] Cuando les acostumbras a que los grupos sean mixtos, ya aparecen conductas naturales de ponerse juntos. Del resultado de eso, cuando pones pongo a algún grupo libre claro que me encuentro casos en que chicos y chicas se ponen juntos (Entrevista maestra1)

Alumno: Estamos, por ejemplo, 2 ó 3 de cada curso en cada grupo.

Alumna: Somos una mezcla heterogénea, como dijo G.

Investigadora: ¿qué significa eso?

Alumna: Que hay una mezcla, que hay una diversidad.

(GD alumnado2)

Estas acciones contribuyen a comprender la diversidad connatural que existe en los grupos humanos y, muy especialmente, a percibir esa diversidad como una oportunidad para el aprendizaje y el enriquecimiento. Igualmente, se trata de transitar de relaciones de competitividad a relaciones de colaboración, sustentadas en el respeto y en el cuidado, que están en la base de la convivencia democrática.

Tenemos un grupo asignado durante todo el curso, todo el año con un profesor. Luego, igual al año que viene, cambiamos. Hacemos otra mezcla porque este año han sido grupos diferentes a los del año anterior para que se enriquezca más esa convivencia y ese conocimiento de los niños (GD docentes)

Referentes adultos: el papel del equipo directivo.

Los esfuerzos por transformar los estereotipos de masculinidad y feminidad tradicionales serán fútiles si los propios docentes no se erigen en modelos que practiquen cotidianamente valores y actuaciones anudados con la igualdad y equidad de género. De poco serviría, por ejemplo, el desarrollo de las actividades mencionadas si los alumnos encontraran un equipo directivo solamente conformado por varones ejerciendo un liderazgo autocrático. $\mathrm{O}$, como es también habitual, un grupo directivo donde los cargos decisorios los ostentan los hombres mientras una mujer ejerce labores de secretaria.

[El equipo directivo se compone de] Ahora tres mujeres. Algo atípico. He estado trabajando 25 años en este colegio, la media de hombres es de... 5 hombres por 35 mujeres, y he estado 20 años con un mismo equipo directivo: primero, 2 hombres y una mujer, y luego 3 hombres. Cuando había ese equipo directivo, el liderazgo era absolutamente autoritario. Además, era curioso, porque no lo compartían los 3 agentes del equipo directivo, sino que era totalmente autoritario del director (Entrevista maestra1).

Actualmente la escuela cuenta con una dirección conformada únicamente por mujeres, lo cual supone bastante coherencia si consideramos la proporción de docentes varones que trabajan en el centro: un $20 \%$ frente a un $80 \%$ de mujeres. Sin embargo, es esta una transformación producida en el último lustro.

Observamos, además, que este equipo conformado por mujeres acaudala un conocimiento profundo del contexto y establece una relación estrecha con todo el claustro, buscando de manera constante engendrar espacios de trabajo caracterizados por las relaciones horizontales en la toma de decisiones.

Ellas delegan mucha responsabilidad en todos los maestros y sobre todo se dedican a coordinar las diferentes estructuras, por ejemplo, a estos equipos impulsores. Sí que es verdad que todo pasa la criba del equipo directivo, porque tienen que estar informadas, pero confían plenamente en el buen hacer de cada equipo impulsor (Entrevista maestra1). 
De hecho, el papel del equipo directivo y la orientadora ha resultado fundamental en la dinamización de estas iniciativas y procesos de cambio desde una perspectiva de género, y también en la generación de las estructuras espacio-temporales que posibilitan la coordinación y el diálogo.

Yo creo que la clave es generar espacios y tiempos en el centro, generar espacios de participación entre el profesorado. Si no generas esos espacios te come el día a día. Necesitas un espacio para pensar y diseñar esas actividades. Tienes que buscar el espacio para compartir (GD docentes).

Estas apreciaciones constatan los hallazgos de investigaciones recientes (Hallinger et alii, 2016) que destacan la inclinación de las mujeres a ejercer liderazgos más distribuidos y participativos, a pesar de encontrar más rémoras en su camino para acceder a cargos de responsabilidad y poder. Precisamente, la desigualdad histórica que ha relegado a las mujeres al ámbito privado y a las funciones de cuidado, afecto $e$ interdependencia, donde se espera que prioricen las necesidades de otros por encima de las individuales, puede explicar en parte estas diferencias en el ejercicio de un liderazgo que se sostiene en la colaboración y en la escucha. No obstante, hablar de liderazgo según características femeninas o masculinas es resultado de esos modelos de género hegemónicos aquí cuestionados. Consideramos esencial favorecer una escuela coeducativa que priorice la convivencia, la interdependencia y las alianzas entre todos los alumnos (cuestionando y subvirtiendo igualmente los estereotipos predominantes) en aras de favorecer formas de liderazgo más solidarias y colaborativas independientemente del sexo de quien lo ejerza (Reverter y Medina, 2017).

Los estudiantes hablan sobre el proyecto: ¿qué hemos aprendido?

En este último apartado pretendemos ilustrar cómo las acciones emprendidas en el centro generan cambios en las actuaciones e imágenes de los niños y niñas en relación a la igualdad y equidad de género:

Alumno: Me ha gustado porque hemos aprendido que los hombres no son más importantes que las mujeres, todos tienen que ganar lo mismo.

Alumna: Hablamos de la igualdad de género porque dicen que los hombres pueden hacer más cosas que las mujeres y las mujeres pueden hacer lo mismo que los chicos, los mismos deportes y trabajos de los chicos. (GD alumnado1)

Si miramos atentamente, descubrimos que las actividades emprendidas han permitido al alumnado repensar sus ideas y acciones y descubrir sus prejuicios. Prender en el alumnado una auto-mirada crítica les aporta excelentes herramientas para detectar situaciones de exclusión y micromachismos.

Alumna: Luego en otra vinieron unas chicas que tenían un trabajo que tradicionalmente los hacían los hombres. Por ejemplo, vino una señora que trabajaba en el parque de Cabárceno que daba de comer a los animales. O una chica que era camionera, que eso es algo que siempre se ha visto que hacen los hombres.

Investigadora: ¿̇vosotros sabíais quién iba a venir?

Alumno: Yo no me esperaba que fuera una camionera. Algunos me sorprendieron mucho, no me los esperaba.

Alumna: Y nosotros los de $1^{\circ}$ salimos afuera y fuimos viendo todas las imágenes que habían puesto de sus profesiones y estuvimos pensando quién iba a venir y nos pensamos que iban a venir unos chicos y unas chicas a la vez.

Alumna: Es que no se suele ver a una camionera y a una bombera. (GD alumnado2)

Una de las reflexiones más recurrentes en los diálogos con el alumnado recae en la ruptura del binomio masculino-femenino con relación a las actividades, juegos y deportes (Martínez y Ramírez, 2017; Tomé, 2017). 
Alumno: Me ha gustado porque muchos niños y gente de mi clase les ha ayudado a pensar que las mujeres y los hombres son iguales.

Alumna: Aprendimos que las mujeres pueden hacer lo que quieran igual que los hombres.

Alumna: Que pueden hacer las mismas cosas que los chicos: jugar al fútbol, al baloncesto, al rugby...

Alumna: Y que también los niños pueden hacer deportes de "chicas". Mi hermano por ejemplo hace baile.

Alumno: y yo también hago baile. Y patinaje.

Alumno: La jugadora de Rugby también decía que le resultaba más difícil que a los chicos ser jugadora porque no le apoyaban tanto. Que a los chicos les pagaban los viajes, el hotel. A las chicas no, solo la equipación. (GD alumnado1)

Destacábamos que la elección de las actividades y desarrollo profesional está enormemente influenciada por los estereotipos de género (Swain, French y Cameron, 2003), teniendo un mayor grado de aceptación incumplir la norma de género para las niñas que para los niños (Álvarez et alii, 2017). En el ejemplo que aparece a continuación, se comprueba cómo la equidad cristaliza en la vida diaria de la escuela eliminando sesgos de género y también rearticulando el reconocimiento y la valoración de algunas actividades consideradas tradicionalmente como femeninas:

Incluso este año, pequeños comentarios que salen en la vida normal del aula, pues qué queremos ser de mayores, ahora que empezamos a trabajar con las profesiones, y ves que un niño, en este caso un niño gitano que él quiere de mayor ser peluquero y no pasa nada. y no pasa nada. Nadie pone caras raras. Un niño gitano que quiere ser peluquero y no pasa nada. Y una niña que quiere ser jugadora de rugby, porque ha visto un ejemplo que seguir y no pasa nada. Entonces ese "no pasa nada" es "Ha servido de mucho". (GD docentes)

Por otro lado, en torno a la temática de género coexisten conceptos de gran complejidad presentes en el lenguaje común. Así, ideas como feminismo, machismo, estereotipo, etc. son frecuentes en los discursos públicos, con sentidos y usos diversos o, incluso, contradictorios. Favorecer que el alumnado comprenda con profundidad estos conceptos de enorme complejidad les otorga herramientas para entender y dar respuesta a los discursos sociales:

Alumno: Vimos otro anuncio de un chico que estaba con el taladro y la mujer tenía que limpiar lo del taladro. El hombre tenía que usar el taladro porque la mujer no sabía.

Alumna: eso se llama machismo.

Alumno: y lo de las chicas feminismo.

Alumna: Porque el feminismo no pretende la superioridad, sino la igualdad. Y el machismo cree que los hombres son superiores. (GD alumnado1)

A modo de síntesis, nos gustaría concluir con la reflexión de una alumna que recoge con enorme seriedad el sentido último de todas las acciones que emprende el centro.

Alumna: me ha gustado mucho, me parece un tema muy importante y me parece que mucha gente ha cambiado de opinión en muchas cosas. Hay gente en nuestra clase que no pensaba que los chicos y las chicas eran iguales y han cambiado de opinión. Había gente que pensaba que las mujeres éramos menos y que no podíamos hacer determinadas cosas y han rectificado determinadas cosas. Y también que nosotras éramos las que fregaban, las que ordenaban todo... y ahora ya han cambiado lo que piensan. (GD alumnado1)

\section{Conclusiones}

En este artículo analizamos, desde un enfoque etnográfico, las claves introducidas en el currículum y en la organización escolar que facilitan que un centro educativo camine hacia los principios de la coeducación, hacia una escuela que apuesta por eliminar las discriminaciones sexistas y construir otros modelos de género y relación (Ballarín, 2001; Subirats, 2017). 
Destacamos una primera clave que refiere a la necesidad de generar redes de colaboración entre personas de la comunidad educativa (Berg, 2018) que tienen una sensibilidad particular por la igualdad. Personas que atesoran un conocimiento hondo del contexto y que piensan juntas acciones e impulsan propuestas, siempre desde la aceptación de que los cambios profundos requieren tiempo para la sensibilización, formación, análisis y acción. Esta idea se materializa en el Manuel Llano a partir de los equipos impulsores. Gracias al equipo consagrado a la Acción Tutorial, el centro emprende un proceso de auto-reflexión desde el punto de vista de la coeducación que revierte en un claustro cada vez más concienciado. Este equipo es también el encargado de dinamizar actuaciones en diferentes ámbitos (organizativos, curriculares...) que coadyuvan a fortalecer los procesos de análisis y el abordaje de contenidos encauzados a la educación para la igualdad y la equidad.

Así, este grupo de personas sensibles con la coeducación ha diseñado acciones curriculares dirigidas al centro en su conjunto y destinadas, en un primer nivel, a analizar las actitudes y comportamientos sexistas que prevalecen en la sociedad y en las relaciones cotidianas (actividades para descubrir prejuicios y estereotipos) y, en un segundo nivel, a construir universos semánticos en torno a lo que significa ser mujer y hombre diferentes a los hegemónicos (Fernández-González y González-Clemares, 2015; Pallarès, 2012). De otro lado, se proponen actuaciones alineadas con la igualdad y la equidad de género que modifican el proyecto educativo, como la revisión de los materiales de aula o la rearticulación de los espacios escolares (Tomé, 2017). Respecto a este último asunto, las acciones inciden tanto en los espacios académicos -decisiones metodológicas que subviertan la inclinación a la auto-segregación sexual (Camps y Vidal, 2015), como los grupos cooperativos a partir de equipos mixtos-, como en los no académicos -dinamizar los recreos para ofrecer una diversidad de actividades lúdicas que sean afines a las diferentes habilidades y preferencias, evitando que una sola actividad se imponga sobre el resto-. Se ha constatado también que cuando los niños y niñas pueden tomar decisiones y participar de los cambios, la implicación y el compromiso con los acuerdos es mayor que si es impuesto.

Finalmente, descubrimos la importancia de ofrecer referentes que encarnen en su quehacer cotidiano los axiomas de la coeducación. Así, por ejemplo, estructuras directivas conformadas por mujeres son esenciales para contravenir algunos estereotipos hondamente cincelados. En la misma línea, involucrar a la familia en estos proyectos y extender las actuaciones en igualdad y equidad de género a otros contextos fuera de la escuela también resulta fundamental para fortalecer la coeducación, pues escuela y familia son los dos agentes de socialización fundamentales. Precisamente, el poder influenciador más grande radica en la congruencia de los mensajes emitidos (Ferrer y Bosch, 2013).

\section{Referencias bibliográficas}

ALBURY, Kath; BYRON, Paul. Safe on My Phone? Same-sex Attracted Young People's Negotiations of Intimacy, Visibility, and Risk on Digital Hook-up Apps. Social Media and Society, 2 (4), United Kingdom, 2016, pp.1-10 [https://doi.org/10.1177/2056305116672887].

ÁLVAREZ, Nuria et alii. ¿̇Juegos de niñas y juegos de niños? La influencia de los estereotipos de género en la elección de juguetes. Revista de estudios e investigación en psicología y educación, 5, España-Portugal, 2017, pp.330-333 [https://doi.org/10.17979/reipe.2017.0.05.2830].

ANGROSINO, Michael. Etnografía y observación participante en la investigación cualitativa. Madrid, Morata, 2012.

ANGUITA, Rocío; TORREGO, Luis. Género, educación y formación del profesorado retos y posibilidades. Revista interuniversitaria de formación del profesorado, 64, España, 2009, pp.17-26.

ARISTIZABAL, Pilar et alii. La mirada coeducativa en la formación del profesorado. Revista Complutense de Educación, 29 (1), España, 2018, pp.79-95 [https://doi.org/10.5209/RCED.52031].

ARISTIZABAL, Pilar et alii. Yo elijo, tú eliges, ellas eligen. Orientación y toma de decisiones de las chicas en la escuela. Revista Española de Orientación y Psicopedagogía, 28 (3), España, 2018, pp.99-114 [https://doi.org/10.5944/reop.vol.28.num.3.2017.21621]. 
BALLARÍN, Pilar. La educación de las mujeres en la España contemporánea (siglos XIX-XX). Madrid, Síntesis, 2001.

BALLARÍN, Pilar. Memoria de la educación de las mujeres. In: LOMAS, Carlos (org.). Lecciones contra el olvido. Memoria de la educación y educación de la memoria. Barcelona, Octaedro, 2011, pp.77-110.

REVERTER, Sonia; MEDINA, María. Intersecciones entre liderazgo y feminismo. Dossiers feministes, 22, Francia, 2017, pp.5-12 [http://hdl.handle.net/10234/168603].

BEAUVOIR, Simone de. El segundo sexo. Buenos Aires, Siglo XX, 1981.

BERG, Jill. Leading together/syncing behavior strategies. Educational Leadership, 76 (1), United States, 2018 , pp.74-85.

BRAGG, Sara et alii. 'More than boy, girl, male, female': exploring young people's views on gender diversity within and beyond school contexts.Sex Education, 18 (4), United Kingdom, 2018, pp.420-434 [https://doi.org/10.1080/14681811.2018.1439373].

CALVO, Adelina et alii. El largo camino hacia la coeducación. Un análisis de las etapas de la educación de las mujeres a partir de tres relatos de vida escolar. Revista de Educación, 354, España, 2011, pp.549-573 [https://doi.org/10.4438/1988-592X-RE-2011-354-011].

CAMPS, Jaume; VIDAL, Enric. Marte y Venus en el aula: las percepciones del alumnado sobre los efectos psicosociales en la escolarización mixta y diferenciada. Revista Española de Pedagogía, 73 (260), España, 2015, pp.53-71 [https://revistadepedagogia.org/lxxiii/no-260/marte-y-venus-en-el-aula-la-percepcion-delalumnado-sobre-los-efectos-psicosociales-de-la-escolarizacion-mixta-y-diferenciada/101400010428/].

DE LA PEÑA, Eva. Proyecto Némesis. El maletín de coeducación para el profesorado. Fórmulas para la igualdad. Mancomunidad de Municipios, Valle del Guadiato, 2007.

DRUDY, Sheelagh. Gender Balance/Gender Bias: The Teaching Profession and the Impact of Feminisation. Gender and Education, 20 (4), United Kingdom, 2008, pp.309-323 [https://doi.org/10.1080/09540250802190156].

EURYDICE. Gender differences in Educational outcomes. Study on the measures taken and the current situation in Europe. European Commission, 2010 [https://op.europa.eu/en/publication-detail//publication/40271e21-ca1b-461e-ba23-88fe4d4b3fd4].

FERNÁNDEZ-GONZÁLEZ, Noelia; GONZÁLEZ-CLEMARES, Nuria. La LOMCE a la luz de la CEDAW. Un análisis de la coeducación en la última reforma educativa. Journal of Supranational Policies of Education, 3, España, 2015, pp.242-263 [https://revistas.uam.es/jospoe/article/view/5650].

ESTEVE, José. Paradojas de la discriminación en materia educativa. El cronista del Estado social y democrático de derecho, 37, España, 2013, pp.4-13.

FERRER, Vicente; BOSCH, Esperanza. Del amor romántico a la violencia de género. Para una coeducación emocional en la agenda educativa. Revista de currículum y formación del profesorado, 17 (1), España, 2013, pp.105-122.

FIRESTONE, Shulamith. La dialéctica del sexo: en defensa de la revolución feminista. Barcelona, Editorial Kairós, 1976.

FISHER, Stephanie; JENSON, Jennifer. Producing Alternative Gender Orders: A Critical Look at Girls and Gaming. Learning, Media and Technology, 42 (1), United Kingdom, 2017, pp.87-99 [https://doi.org/10.1080/17439884.2016.1132729].

FONTELA, Marta. ¿Quées el patriarcado? En: GAMBA, Susana, Diccionario de estudios de género y feminismos, Buenos Aires, Biblos, 2007.

GARCÍA-LASTRA, Marta. La perspectiva de género en la formación inicial del profesorado de educación infantil. Notas sobre una investigación realizada entre el alumnado del grado de magisterio de educación infantil de la Universidad de Cantabria (España). Ex æquo, 36, Portugal, 2017, pp.43-57.

JEFFREYS, Sheila. La Herejía Lesbiana. Una perspectiva feminista de la revolución sexual lesbiana. Madrid, Ediciones Cátedra, 1996.

LERNER, Gerda. La creación del patriarcado. Barcelona, Editorial Crítica, 1990. 
GRAÑERAS, Montserrat et alii. Agentes para la igualdad de género en los centros educativos: el caso de las CCAA de España en perspectiva supranacional. Journal of Supranational Policies of Education, 3, España, 2015, pp.219-241.

HALLINGER, Philip et alii. Gender differences in instructional leadership: A meta-analytic review of studies using the principal instructional management rating scale. Educational Administration Quarterly, 52 (4), United States, 2016, pp.567-601.

KIM, Cristal; RINGROSE, Jessica. 'Stumbling upon Feminism': Teenage Girls' Forays into Digital and SchoolBased Feminisms. Girlhood Studies, 11 (2), United States, 2018, pp.46-62.

LAURETIS, Teresa. Technologies of Gender: essays in theory, film, and fiction. Bloomignton, Indiana University Press, 1987.

LÓPEZ-NAVAJAS, Ana. Análisis de la ausencia de las mujeres en los manuales de la ESO: una genealogía de conocimiento ocultada. Revista de Educación, 363, España, 2014, pp.282-308.

MARTÍNEZ, Irene; RAMÍREZ, Gema. Des-patriarcalizar y des-colonizar la Educación. Experiencias para una formación feminista del profesorado. Revista Internacional de Educación para la Justicia Social (RIEJS), 6 (2), Madrid, 2017, pp.81-95.

MILLETT, Kate. Politica Sexual. Madrid, Ediciones Cátedra, 2010.

MORIANA, Gabriela. Educación en igualdad de género para prevenir la violencia machista. Cuestiones de género: de la igualdad y la diferencia, 12, España, 2017, pp.267-286.

MORRISON, Ann et alii. Breaking the glass ceil-ing. Readin, Addison-Wesley, 1987.

PALLARÉS, Marc. La cultura de género en la actualidad: actitudes del colectivo adolescente hacia la igualdad. Tendencias Pedagógicas, 19, España, 2012, pp.189-209.

PARRA, Juan. Educación en valores y no sexista. La Mancha, Instituto de la Mujer de Castilla-La Mancha, 2009.

PELLEGRINI, Anthony et alii. A short-term longitudinal study of preschoolers' (Homo sapiens) sex segregation: The role of physical activity, sex, and time. Journal of Comparative Psychology, 121 (3), United States, 2007, pp.282-289.

QUINN, David; COOC, North. Science Achievement Gaps by Gender and Race/Ethnicity in Elementary and Middle School Trends and Predictors. Educational Researcher, 44 (6), United States, 2015, pp.336-346.

RESTREPO, Eduardo. Etnografía: alcances, técnicas y éticas. Lima, Universidad Nacional Mayor de San Marcos, 2018.

RIST, Ray. Blietzkrieg Ethnography: on the transformation of a method into a movement. Educational Researcher, 9, United States, 1980, pp.8-10.

RUIZ-REPULLO, Carmen. Estrategias para educar en y para la igualdad: coeducar en los centros. ATLÁNTICAS. Revista Internacional de Estudios Feministas, 2 (1), España, 2017, pp.166-191.

SCOTT, Joan. El género: una categoría útil para el análisis histórico. 1986.

SIMÓN, María Elena. La igualdad también se aprende. Cuestión de coeducación. Madrid, Narcea, 2010.

SUBIRATS, Marina. Educar con el compromiso social y la perspectiva de género. Un reto el cambio cultural. Aula de innovación educativa, 267, España, 2017, pp.11-14.

SUBIRATS, Marina. De los dispositivos selectivos en la educación: el caso del sexismo. Revista de la Asociación de Sociología de la Educación, 9 (1), España, 2016, pp.22-36.

SWAIN, John; FRENCH, Sally; CAMERON, Colin. Controversial issues in a disabling society. Buckingham, Open University Press, 2003.

TOMÉ, Amparo. Estrategias para elaborar proyectos coeducativos en las escuelas. ATLÁNTICAS, Revista Internacional de Estudios Feministas, 2(1), España, 2017, pp.89-116.

TORRES, Jurjo. Diversidad cultural y contenidos escolares. Revista de Educación, 345, España, 2008, pp.83110. 
VELASCO, Honorio y DÍAZ DE RADA, Ángel. La lógica de la investigación etnográfica. Un modelo de trabajo para etnógrafos de escuela. Madrid, Trotta, 2006.

VIÑAO, Antonio. Sistemas educativos, culturas escolares y reformas. Madrid, Morata, 2002.

\section{Referencias legislativas}

Ley 39/1999, de 5 de noviembre, para promover la conciliación de la vida familiar y laboral de las personas trabajadoras. Boletín Oficial del Estado. Madrid, 6 de Noviembre de 1999, n. 266, pp.38934-38942.

Ley Orgánica 1/2004, de 28 de diciembre, de Medidas de Protección Integral contra la Violencia de Género. Boletín Oficial del Estado. Madrid, 29 de diciembre de 2004, n. 313, pp.42166-42197.

Ley Orgánica 2/2006, de 3 de mayo, de Educación. Boletín Oficial del Estado. Madrid, 4 de Mayo de 2006, n. 106, pp.17158-17207.

Ley Orgánica 3/2007, de 22 de marzo, para la igualdad efectiva de mujeres y hombres. Boletín Oficial del Estado. Madrid, de 23 de marzo de 2007, n. 71, pp.12611-12645.

Ley Orgánica 8/2013, de 9 de diciembre, para la mejora de la calidad educativa. Boletín Oficial del Estado. Madrid, 10 de diciembre de 2013, n. 295, pp.97858-97921. 